\title{
Improving anaerobic conversion of pulp mill secondary sludge to biogas by pretreatment
}

\author{
NICHOLAS WOOD, HONGHI TRAN, AND EMMA MASTER
}

\begin{abstract}
We examined the effectiveness of thermal, caustic, and sonication pretreatment methods in improving anaerobic conversion to biogas of secondary sludge samples obtained from a kraft mill and a sulfite mill. All three methods improved the anaerobic digestion rate and the biogas yield of the sludge samples. Thermal pretreatment was the most effective, followed closely by caustic pretreatment, and sonication the least. The total biogas productions per unit of chemical oxygen demand of sulfite sludge and kraft sludge samples were respectively 1.2 and 3 times higher with pretreatments than without. Also, the biogas production from the untreated sulfite mill sludge was 4 times higher than that from the untreated kraft mill sludge.
\end{abstract}

Application: The soluble carbohydrate content in sludge correlates well with the biogas yield and can be used to predict the biogas production potential of the secondary sludge.

$\mathbf{W}$ astewater in pulp and paper mills is typically treated in two steps: (1) primary treatment, which removes lignocellulosic solids in the wastewater, and (2) secondary treatment, which removes the soluble organic matter. Aerobic biological wastewater treatment systems are commonly used for secondary treatment. In these systems, aerobic microorganisms take oxygen $\left(\mathrm{O}_{2}\right)$ in air to convert the soluble organic matter into carbon dioxide $\left(\mathrm{CO}_{2}\right)$, water $\left(\mathrm{H}_{2} \mathrm{O}\right)$, and microbial biomass, which consists of flocs of microorganisms and insoluble aggregates of biopolymers. Flocs settle out of the treated wastewater at the bottom of the treatment system, forming biological matter known as secondary sludge and leaving a clean effluent for discharge.

Depending on the pulping process, the amount of secondary sludge generated can be substantial, about $60 \mathrm{~kg}$ solids per air-dried metric ton (a.d. ton) sulfite pulp and about $100 \mathrm{~kg}$ solids/a.d. ton kraft pulp produced [1]. This amounts to an annual production of 5 million dry tons of sludge that need to be disposed of in Canada and the USA. Landfilling and incineration are the most common methods of sludge disposal, although sludge needs to be dewatered to reduce its volume/ weight sent to landfill and to make its combustion more efficient. Because of the high water content of the sludge even after dewatering, the cost of sludge disposal accounts for as much as $60 \%$ of the total wastewater treatment costs [2]. In many pulp mills, secondary sludge disposal has become an increasingly important economic and environmental issue.

Anaerobic digestion is an alternative method for secondary sludge disposal $[2,3,5,6]$. In this process, anaerobic microorganisms transform the organic matter in the sludge into biogas, which consists of about $65 \%$ methane $\left(\mathrm{CH}_{4}\right)$ and thus can be used as a replacement for natural gas. Anaerobic diges- tion does not require aeration, so it produces about one-tenth of the sludge generated by an aerobic system. A disadvantage, however, is the slow growth of anaerobic microorganisms; therefore, anaerobic digestion requires a large reactor with sufficiently long residence time [4]. This disadvantage is the main reason why anaerobic digestion has not been widely adopted in industrial applications.

In recent years, several types of high-rate anaerobic digesters have been developed to decouple the residence time of the anaerobic microorganisms from that of the wastewater. One type is the upflow anaerobic sludge blanket (UASB) reactor, which accounts for half of all anaerobic digesters in various industrial applications. Of about 800 UASB installations worldwide, 75 are at pulp and paper mills [5].

In a UASB digester, anaerobic microorganisms are retained within the reactor for several days while wastewater flows through the reactor in several hours. This is possible because microorganisms form granules (1 to 2 -mm-diam aggregates) that

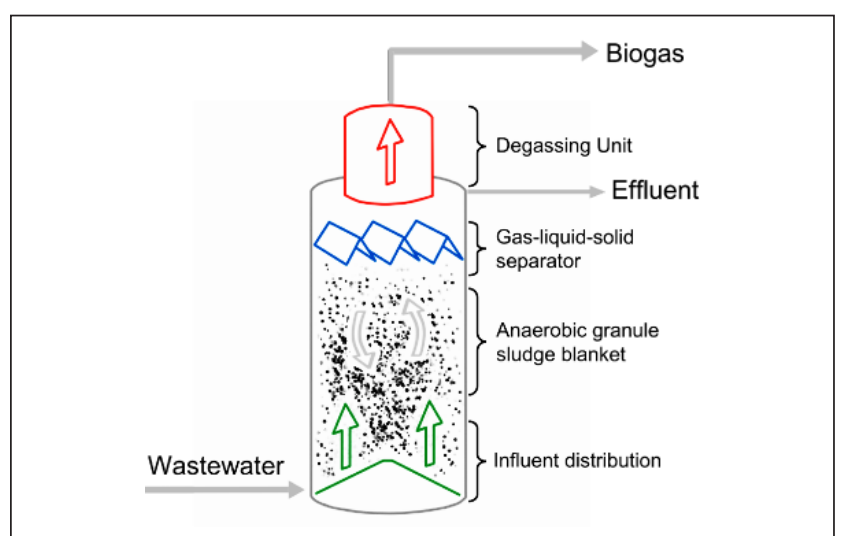

1. Upflow anaerobic sludge blanket reactor. 


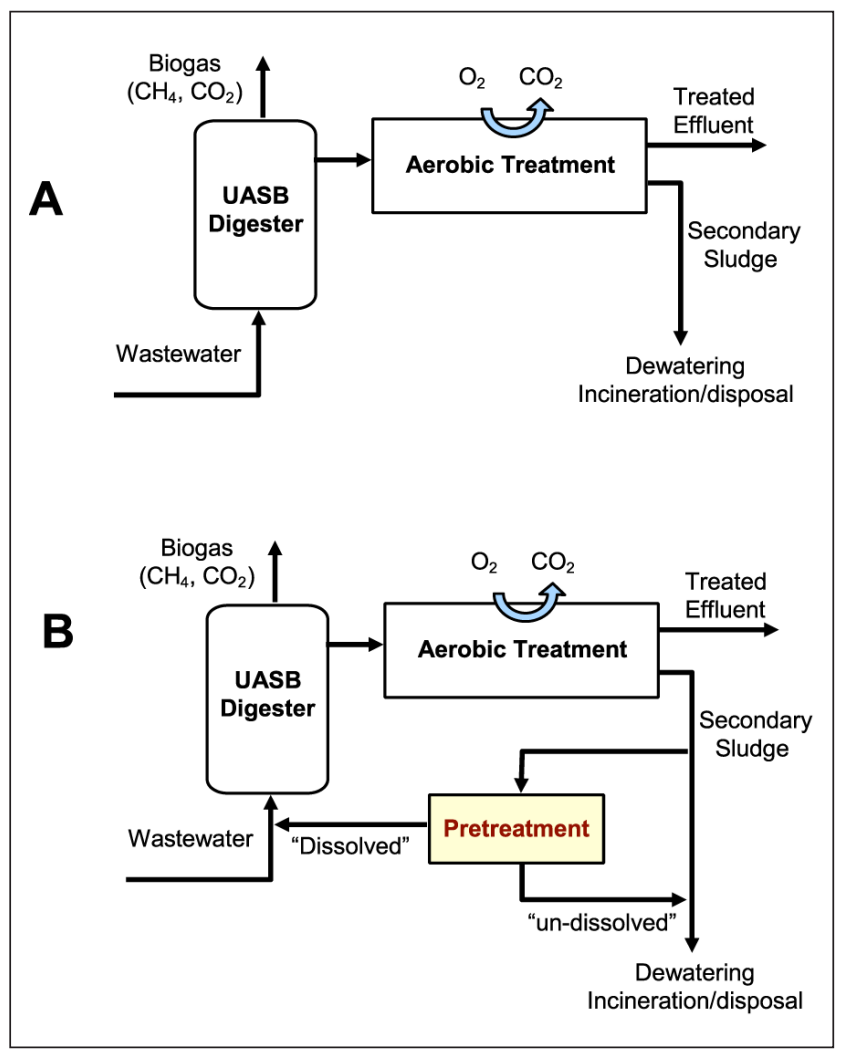

2. Wastewater treatment system incorporating a highrate anaerobic digester without $(A)$ and with $(B)$ a sludge pretreatment system.

can readily settle. Figure 1 shows how wastewater flows upward through the reactor around the granules and creates a suspension of microorganisms that are continuously settling. Methane and $\mathrm{CO}_{2}$ produced in the process are collected at the top of the reactor. This makes the reactor volume smaller than conventional anaerobic digesters while retaining high biogas conversion efficiency. However, a high-rate anaerobic digester can remove only a portion of the organic matter from the wastewater stream, so it is often coupled with an aerobic treatment system [6], as shown in Fig. 2.

It is technically possible to treat at least a portion of the waste generated from pulp and paper mills in traditional anaerobic digesters [2]. Treating a portion of secondary sludge in a UASB reactor has the potential to greatly reduce the amount of sludge requiring disposal, while producing biofuel that could displace natural gas in mill processes. The challenge is, although the majority of organic matter in secondary sludge is anaerobically digestible, insoluble components and lignin are more difficult for anaerobic microorganisms to hydrolyze [7]. As a result, a long residence time (30-60 days) is required. A possible solution is to use a pretreatment method that physically and chemically hydrolyzes and solubilizes the secondary sludge before feeding it to a UASB digester (Fig. 2).

Several pretreatment methods have been studied with municipal sewage sludge, but none have involved pulp and paper mill sludge. We conducted a laboratory study to systemati- cally investigate the effectiveness of three common pretreatment methods in enhancing the anaerobic digestion and biogas production of secondary sludge from pulp mills $[8,9]$. For further details on the experimental procedures and analytical methods we used, see $[8,9]$.

\section{EXPERIMENTAL}

Sludge and granule samples

We used two types of secondary sludge samples: (1) kraft sludge (KS) from a bleached kraft pulp mill that uses an aerobic stabilization basin system to treat its effluent and (2) sulfite sludge (SS) from an ammonium-based sulfite pulp mill that used an activated sludge system and an upflow anaerobic sludge blanket (UASB) digester to treat several mill wastewater streams prior to aerobic treatment. The methanogenic culture used for both SS and KS was microbial granules that formed in the UASB digester at the sulfite mill. Before being tested, the sludge samples were stored at $4^{\circ} \mathrm{C}$ in sealed plastic bags, while the anaerobic granules were stored at $4^{\circ} \mathrm{C}$ in glass serum bottles sealed with butyl rubber stoppers and sparged with a mixture of $80 \%$ nitrogen $\left(\mathrm{N}_{2}\right)$ and $20 \% \mathrm{CO}_{2}$.

\section{Pretreatment methods}

Sludge samples, as received, were dilute water slurries containing less than $20 \mathrm{~g} / \mathrm{L}$ suspended solids. Three different pretreatment methods were applied on the samples before they were subject to anaerobic conversion tests. For each pretreatment, $400 \mathrm{~mL}$ of sludge was used.

1. Thermal pretreatment. The sample was heated in a glass-lined titanium autoclave at $170^{\circ} \mathrm{C}$ for $1 \mathrm{~h}$. The headspace of the autoclave was flushed with $\mathrm{N}_{2}$ to prevent the sample from oxidation. After the treatment, the sample was cooled to room temperature and its $\mathrm{pH}$ was adjusted to 7 with hydrochloric acid $(\mathrm{HCl})$.

2. Caustic pretreatment. Sodium hydroxide $(\mathrm{NaOH})$ pellets were dissolved in the sample slurry to increase its $\mathrm{pH}$ to 12 . The causticized sample was heated in a glass-lined titanium autoclave at $140^{\circ} \mathrm{C}$ for $1 \mathrm{~h}$, cooled to room temperature, and had its $\mathrm{pH}$ adjusted to 7 . As with thermal pretreatment, this neutralization procedure was necessary to bring the pretreated samples to the same conditions as the untreated samples during anaerobic digestion.

3. Sonication pretreatment. The sample was sonicated at $20 \mathrm{kHz}$ to induce cavitations at intensity of 1 $\mathrm{kW} / \mathrm{L}$, using a tubular sonication unit. The pretreatment continued for $30 \mathrm{~min}$. Although the sample temperature steadily increased as a result of sonication, it did not exceed $55^{\circ} \mathrm{C}$.

These methods and experimental conditions were chosen on the basis of an extensive literature review of pretreatments investigated for municipal sewage sludge $[8,9]$. Thermal and caustic pretreatment methods have also been used previously 
to improve sludge dewaterability.

The effectiveness of pretreatment was determined based on the following parameters measured for treated and untreated sludge samples:

1. Total (TSS) and volatile (VSS) suspended solids. TSS indicates the amount of solids, while VSS indicates the amount of organic solids in the sample.

2. Chemical oxygen demand (COD). Total COD and soluble COD fraction were measured according to APHA Standard Method 5220 D [10]. COD represents the total matter in a sludge sample that can be oxidized. It also indicates the amount of available substrate for anaerobic microorganisms to convert to $\mathrm{CH}_{4}[4]$.

3. Carbohydrates. Total and soluble carbohydrates were measured using the anthrone method [11]. They are major components of microbial flocs and are highly anaerobically digestible.

4. Proteins. Proteins are also are a major component of microbial flocs and are usually anaerobically digestible. Soluble protein was measured using a modified version of the Lowry method $[12,13]$.

5. Biogas production. The extension of biogas production was determined using the biochemical methane potential (BMP) assay [14]. This assay is a batch anaerobic digestion conducted in 160-mL glass bottles for up to 34 days. Anaerobic biomass, nutrient medium, and

\begin{tabular}{|l|c|c|}
\hline & $\begin{array}{c}\text { Sulfite } \\
\text { Sludge (SS) }\end{array}$ & $\begin{array}{c}\text { Kraft } \\
\text { Sludge (KS) }\end{array}$ \\
\hline $\begin{array}{l}\text { Total suspended } \\
\text { solids (TSS), g/L }\end{array}$ & 8.7 & 17.9 \\
\hline $\begin{array}{l}\text { Volatile suspended } \\
\text { solids (VSS), g/L }\end{array}$ & 7.3 & 13.9 \\
\hline $\begin{array}{l}\text { Ash in suspended } \\
\text { solids, g/L* }\end{array}$ & 1.4 & 4.0 \\
\hline COD, g/L & 12 & 27 \\
\hline Soluble COD, g/L & 1.4 & 0.3 \\
\hline Soluble COD, \%* & 12 & 1.1 \\
\hline Total carbohydrates, g/L & 0.80 & 2.0 \\
\hline Soluble carbohydrates, g/L & 0.06 & 0.01 \\
\hline Soluble carbohydrates, \%* & 7.4 & 0.50 \\
\hline Total protein, g/L & 3.9 & 4.6 \\
\hline Soluble protein, mg/L & 17 & 6 \\
\hline Soluble protein, \%* & 0.43 & 0.13 \\
\hline pH & 7.4 & 7.0 \\
\hline Sulfate, g/L & 0.20 & 0.60 \\
\hline Calcium, g/L & 0.19 & 0.89 \\
\hline Iron, g/L & 0.18 & 0.04 \\
\hline
\end{tabular}

* Calculated from the two values above.

\section{Composition of sludge samples.}

substrate were added to each bottle. The same amount of substrate was used in terms of COD or VSS, depending on the experiment. Over the course of BMP assay, the amount of biogas produced was measured using a pressure transducer to determine the buildup of gases in the headspace of the bottles. The $\mathrm{CH}_{4}$ concentration of the biogas was measured using a gas chromatograph equipped with a flame ionization detector.

\section{RESULTS AND DISCUSSION \\ Sludge composition}

Table I summarizes the composition of sludge samples used in this study. SS contained much less TSS, VSS, COD, total carbohydrates, and total protein than KS, although the soluble fractions of these components in SS were all higher than those in KS. SS also contained less sulfate, less calcium (Ca), and more iron $(\mathrm{Fe})$ than $\mathrm{KS}$.

\section{Effects of pretreatment methods on sludge properties}

Figure 3 compares the effectiveness of pretreatment methods in reducing the TSS content of SS and KS. Total suspended solids consist of two parts: (1) VSS and (2) ash. The results show that only the VSS content was affected by pretreatments, not the ash content. Figure $\mathbf{4}$ shows the effect of pretreatments on VSS. Thermal and caustic pretreatments reduced

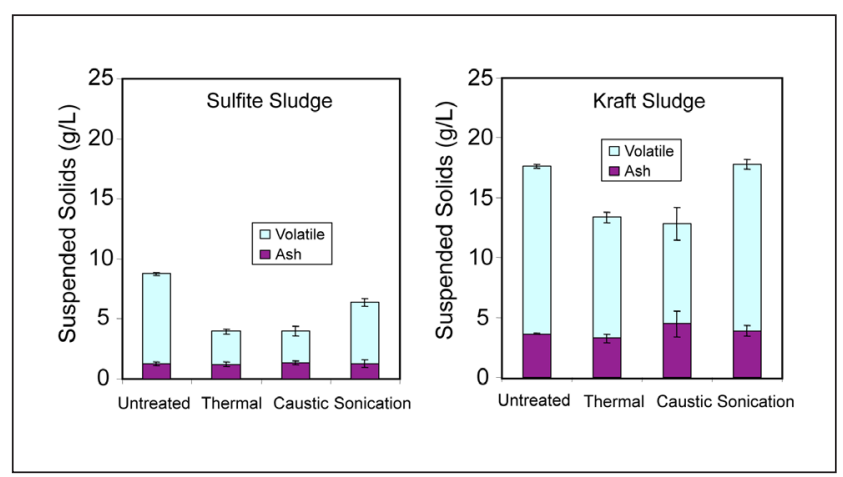

3. Effect of pretreatments on total suspended solids.

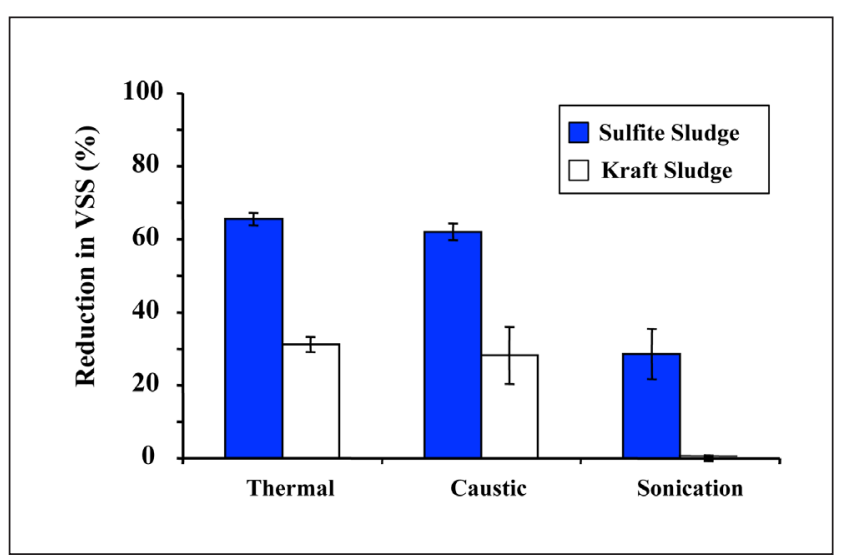

4. Effect of pretreatments on reduction in volatile suspended solids. 


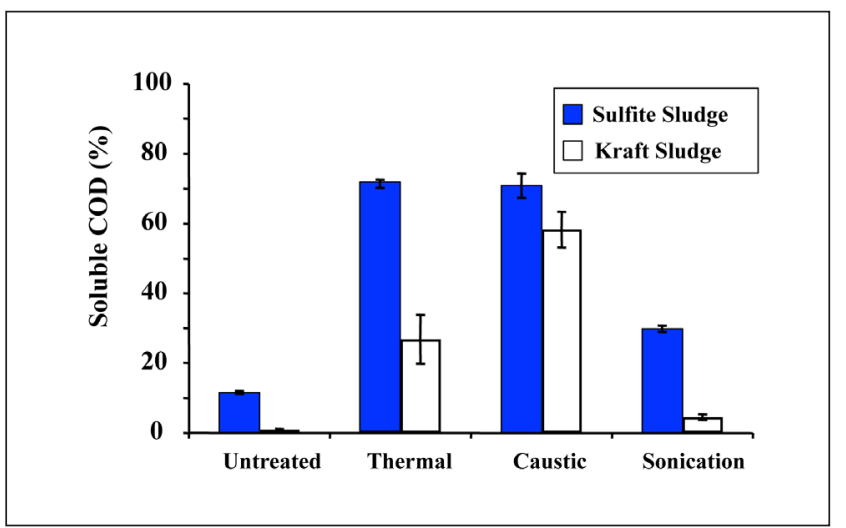

5. Effect of pretreatment methods on soluble COD of secondary sludge samples.

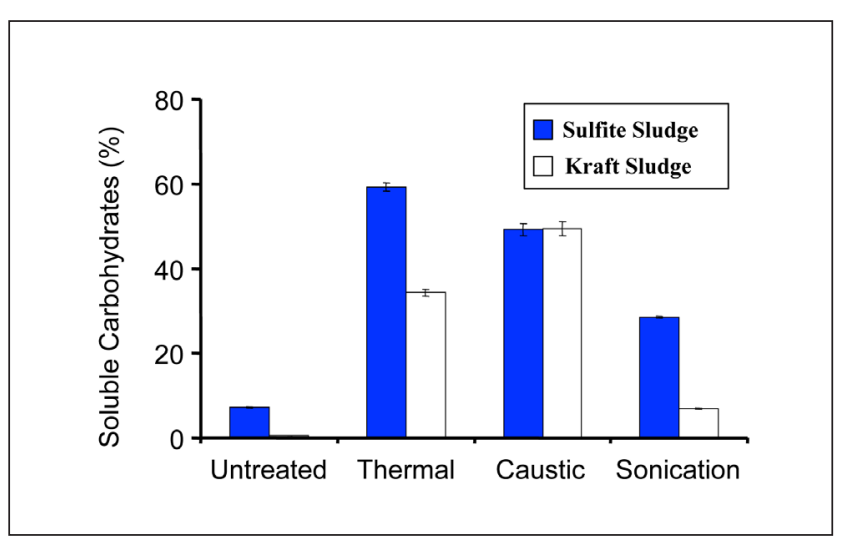

6. Percentage of total carbohydrates that was soluble in untreated and pretreated sludges.

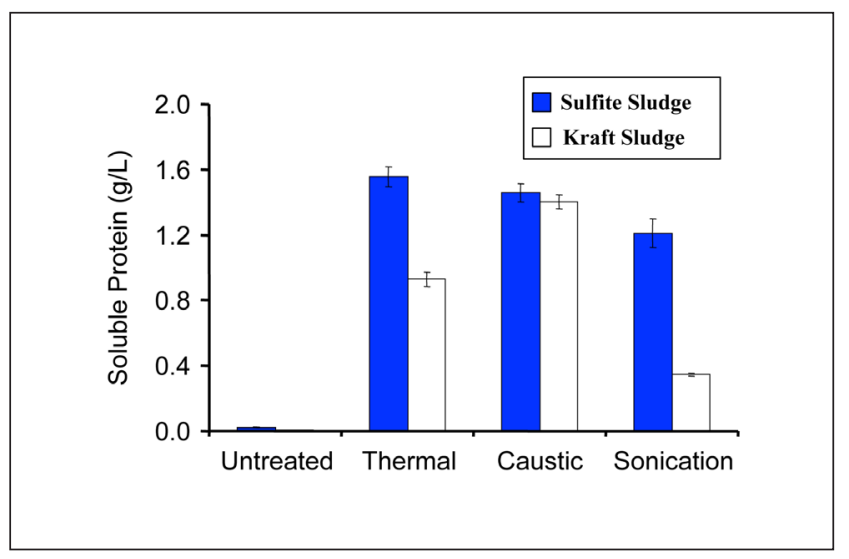

\section{Soluble protein content in untreated and pretreated sludges.}

$60 \%$ of VSS in SS and $30 \%$ in KS. Sonication pretreatment also lowered the VSS content of SS somewhat, but did not appreciably affect that in KS. SS and KS responded differently to pretreatment methods, reflecting the difference in properties of their solids.

Figures 5, 6, and 7 show that when compared with sonication pretreatment, thermal and caustic pretreatments were more effective in solubilizing COD, carbohydrates, and protein in the sludge samples. Carbohydrates and proteins are the

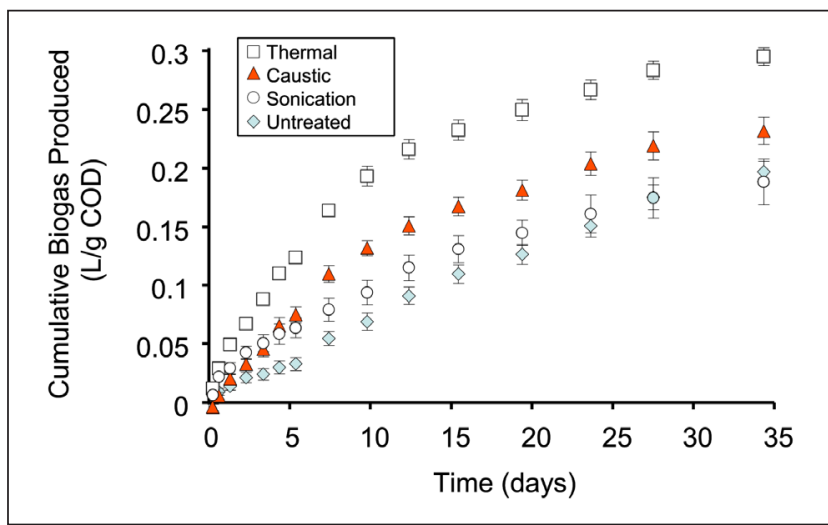

8. Cumulative biogas production from untreated and pretreated sulfite sludge.

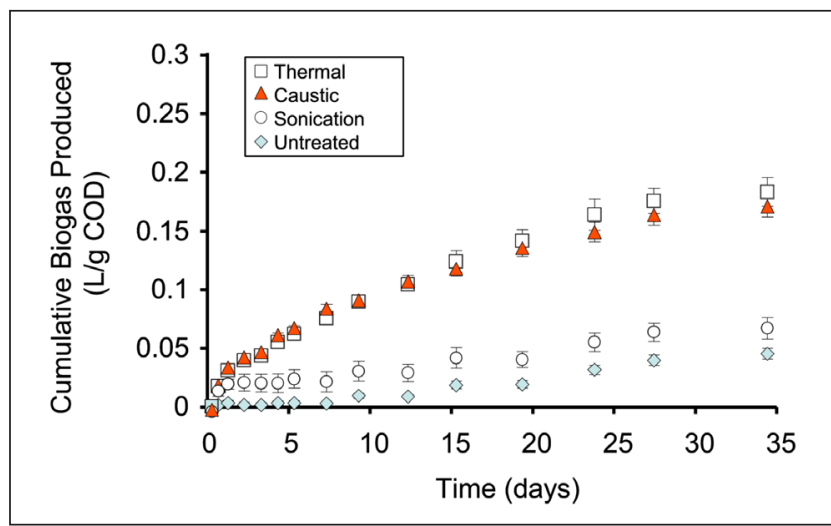

9. Cumulative biogas production from untreated and pretreated kraft sludge.

major components of microbial flocs, so the increase in their soluble fractions in treated sludges implies that microbial flocs were disrupted by pretreatments.

\section{Biogas production}

Figure 8 plots the cumulative amounts of biogas produced from untreated and pretreated SS over a period of 34 days of anaerobic digestion. Thermal and caustic pretreated SS respectively produced $50 \%$ and $18 \%$ more biogas than the untreated SS, whereas the sonication pretreated sludge produced about the same amount of biogas as the untreated SS.

Figure 9 shows that similar results were obtained for KS, although the amount of biogas produced from KS was smaller than that from SS. The results are consistent with the fact that the KS used in our study contained less soluble organic matter than SS (Table I).

The slopes of the curves in the first few days and the heights of the curves at the end of the tests in Figs. 8 and 9 suggest that thermal and caustic pretreatments can significantly increase both the rate (curve slope) and the extent (curve height) of anaerobic bioconversion of pulp mill secondary sludge to biogas.

Figure 10 summarizes the effects of pretreatment methods on the total biogas produced per COD over 34 days of anaerobic digestion. Under a given pretreatment condition, SS 


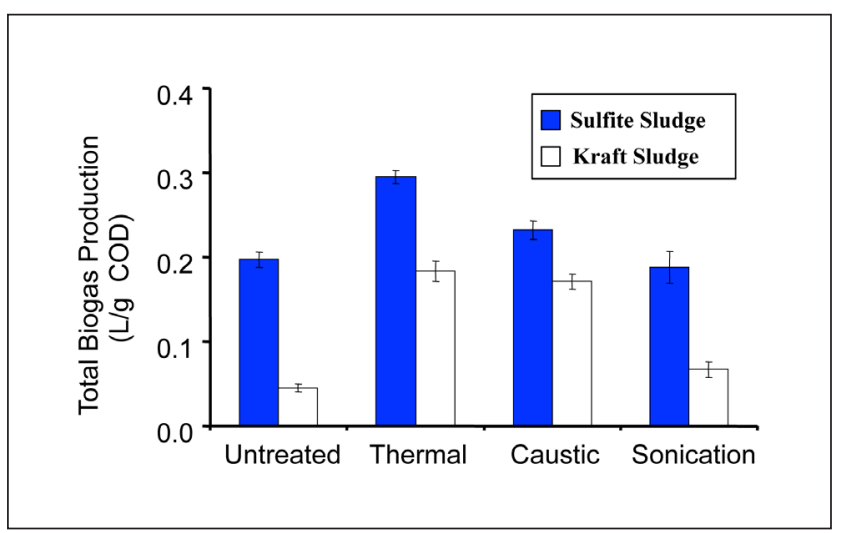

10. Total biogas produced from untreated and pretreated sulfite sludge and kraft sludge at the end of 34 days of anaerobic digestion.

produced more biogas than KS, consistent with its higher soluble organic content. Thermal pretreatment was the most effective in increasing biogas production, followed by caustic pretreatment. Sonication pretreatment was the least effective.

The percentage change in biogas production as a result of pretreatment was smaller with SS than KS because of the high biogas yield of the untreated SS that was readily digestible, producing four times more biogas than untreated KS.

There are two possible reasons for SS to contain more soluble organic matter and be more digestible than KS:

1. The sludges came from two different types of wastewater treatment systems. Sulfite sludge was taken from an activated sludge system where it was continuously removed (or recycled) and thus had little time for anaerobic digestion to occur appreciably. Kraft sludge, on the other hand, was collected from an aerobic stabilization basin where sludge was held for several months in an anoxic zone of an aeration pond. While stored, the sludge would undergo anaerobic digestion and any readily digestible organic matter would be removed.

2. Sulfite sludge contained more iron than kraft sludge. The higher iron content was due to the addition of a nutrient mixture to the wastewater treatment system to improve floc production. Although $\mathrm{Fe}^{3+}$ is important in keeping flocs together, under anaerobic conditions it may be reduced biologically and precipitate out of solution [15]. This may cause microbial flocs to fall apart. Higher iron content improves the anaerobic digestion of aerobic sludges and flocs [16].

We attempted to determine which physical or chemical characteristics were the best predictors of biogas production during BMP assays. We plotted each parameter (soluble COD, soluble carbohydrates, or soluble protein) against total biogas production and performed a linear regression. Figure 11 shows that soluble carbohydrates had the highest degree of linear correlation with total biogas production from both SS and $\mathrm{KS}$, with an $\mathrm{R}^{2}$ value of $>0.90$. Soluble COD and soluble

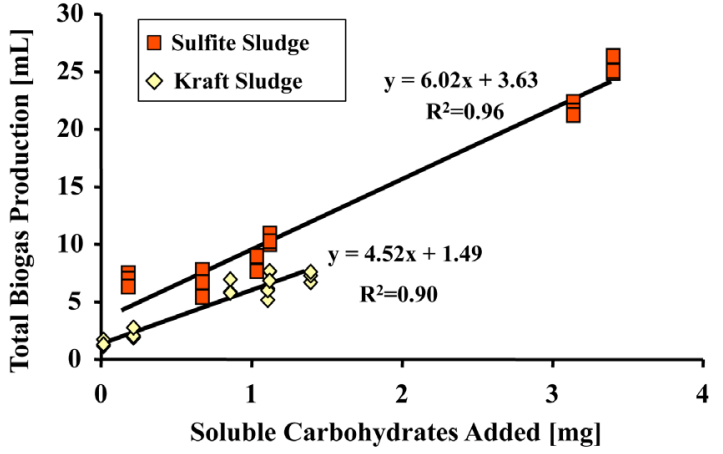

11. Total biogas production versus soluble carbohydrate content of all untreated and pretreated sludge samples.

protein also had good correlation coefficients, but they were not consistent between sludge samples. The results suggest the soluble carbohydrate content may be used as a predictor for the biogas production potential of the sludge.

\section{CONCLUSIONS}

The results of this laboratory study show that thermal pretreatment was the most effective, followed closely by caustic pretreatment and then sonication, in improving the rate and extent of biogas yield of sulfite and kraft sludges. The biogas production from the untreated sulfite mill sludge was four times higher than that from the untreated kraft mill sludge. The results also show that organic components in both types of sludges were predominately solubilized by the pretreatments tested, and biogas yield was correlated well with solubilized carbohydrate, and not COD. The findings imply that the solubilized fraction of pretreated secondary sludge could be used as a feedstock for high-rate anaerobic bioconversion at pulp mill installations. TJ

\begin{tabular}{|lll|}
\hline & & \\
NOMENCLATURE \\
COD & $=$ & Chemical oxygen demand \\
KS & $=$ & Secondary sludge from a kraft mill \\
SS & $=$ & Secondary sludge from a sulfite mill \\
UASB & $=$ & Upflow anaerobic sludge blanket \\
& & reactor \\
TSS & $=$ & Total Suspended Solids \\
VSS & $=$ & Volatile Suspended Solids \\
& & \\
\hline
\end{tabular}

\section{ACKNOWLEDGMENTS}

This work was part of the research program on Alternative Fuels for Lime Kilns, jointly supported by the Natural Sciences and Engineering Research Council of Canada (NSERC); industrial members of the research consortium on Increasing Energy and Chemical Recovery Efficiency in the Kraft Process; and the following companies: Alberta Pacific, Alberta 
Research Council/Alberta Forestry Research Institute, DTE Petcoke, FPInnovations, Jammbco, Kiln Flame Systems, and Zellstoff Celgar.

\section{LITERATURE CITED}

1. Scott, G. M. and Smith, A. TAPPI 1995 International Environmental Conference Proceedings, vol. 1, TAPPI Press, Atlanta, GA, USA, p. 269.

2. Puhakka, J.A., Bioresource Tech. 39: 61(1992).

3. Mahmood, T. and Elliot, A., Water Res. 40: 2093(2006).

4. Rittmann, B.E. and McCarty, P.L., Environmental Biotechnology: Principles and Applications, McGraw-Hill, New York, NY, USA, 2001.

5. Kleerebezem, R. and Macarie, H., Chem. Eng. 110: 56(2003).

6. La Motta, E.J., Silva, E., Bustillos, A., Padrón, H., et al., J. Environ. Eng. 133: 397(2007).

7. Eastman, J.A. and Ferguson, J.F., J. Water Pollution Control Fed. 53: 352(1981).

8. Wood, N., "Pretreatment of pulp mill wastewater treatment residue to improve their anaerobic digestion," Master's thesis, University of Toronto, Toronto, ON, Canada, 2008.

9. Wood, N., Tran, H.N., and Master, E., Bioresource Tech. 100(3): 5729(2009).

10. American Public Health Association, Standard Methods for the Examination of Water and Wastewater, 20th edn., American Public Health Association, Washington, DC, USA, 1998.

11. Raunkjaer, K., Hvitved-Jacobsen, T., and Nielsen, H., Water Res. 28 : 251(1994).

12. Peterson, G.L., Anal. Biochem. 83: 346(1977).

13. Frølund, B., Griebe, T., and Nielsen, P.H. Applied Microbiol. Biotech. 43: 755(1995).

14. Owen, W.F., Stuckey, D.C., Healy, J.B., et al., Water Res. 13: 485(1979).

15. Nielsen, P.H. and Keiding, K., Water Res. 32: 313(1998).

16. Park, C., Abu-Orf, M.M., et al. Water Environ. Res, 78 : 59 (2006).

\section{ABOUT THE AUTHORS}

We undertook this study to be able to develop viable technologies to convert a mill waste stream into a valuable product. Our research complements current genomic analyses of microbial communities that convert recalcitrant biomass into biogas.

Our biggest challenge was to obtain accurate estimates of protein due to the complexity of the feed material. This was resolved through systematic comparison of protocols used to measure protein concentration. We were surprised at the comparatively low impact of sonication on biogas production.

For practical application, mills might use the soluble carbohydrate content of the secondary sludge as a predictor of the biogas production potential. The next step is to increase the range of mill effluents that can be anaerobically converted to biogas.

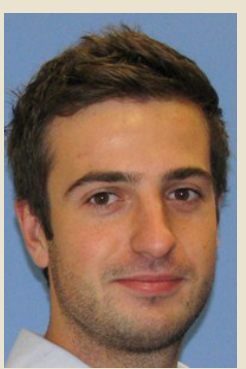

Wood

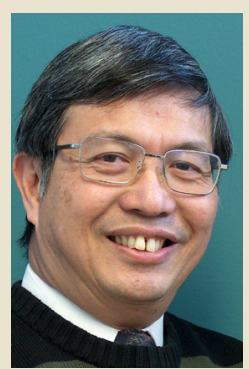

Tran

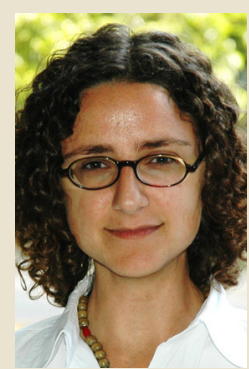

Master
Wood, Tran, and Master are with the Pulp \& Paper Center and Department of Chemical Engineering and Applied Chemistry, University of Toronto, Toronto, ON, Canada M5S 3ES. Email Tran at honghi.tran@utoronto.ca. 